\title{
Perfis de utilização de serviços de saúde no Brasil
}

\author{
Profiles of health services utilization in Brazil
}

Diana Oya Sawyer 1

Iúri da Costa Leite 2

Ricardo Alexandrino 1

\footnotetext{
1 Centro de

Desenvolvimento e

Planejamento Regional/

Cedeplar/UFMG.

Rua Curitiba 832,

9o andar, 30170-120

Belo Horizonte MG.

dsawyer@cedeplar.ufmg.br

2 Departamento de

Epidemiologia e Métodos

Quantitativos em Saúde,

Fiocruz.
}

\begin{abstract}
Health care services are responsible for attending to the population's demand, which is the sum of social, individual and cultural factors. A knowledge of health consumption patterns becomes, thus, necessary. Through the Grade of Membership (GoM) technique, four health consumption profiles were generated for this article. Andersen's theoretical model of health service consumption served as a frame of reference, allowing for health service demand estimates according to high and low levels of enabling, need and predisposing consumption factors. Worthy of notice is the fact that $14 \%$ of the Brazilian population over 14 years of age (excluding the Northern region) present high need and predisposal despite their low enabling characteristics. This group consists predominantly of elderly people living alone and in dire need of specialized services. Key words Utilization of health services, Grade of Membership (GoM), Brazil
\end{abstract}

Resumo Serviços de saúde devem responder às demandas populacionais que resultam da conjugação de fatores sociais, individuais e culturais. Para isso, faz-se necessário o conhecimento do padrão de consumo de serviços de saúde. Neste artigo, quatro perfis de consumo de saúde foram gerados a partir da aplicação da técnica do Grade of Membership (GoM). O modelo teórico de utilização de serviços de saúde proposto por Andersen serviu como marco de referência da análise, permitindo que estimativas da demanda por serviços de saúde fossem feitas segundo níveis altos e baixos de capacitação, necessidade e predisposição para o consumo. Ressalta-se que especial atenção deve ser dada ao grupo de alta necessidade e predisposição, e baixa capacitação, que representa 14\% da população brasileira acima de 14 anos de idade (exceto a região Norte) e é composto, predominantemente, por idosos que moram sozinhos e têm alta necessidade de serviços especializados.

Palavras-chave Utilização de serviços de saúde, Grade of Membership, Brasil 
As demandas por serviços de saúde resultam da conjugação de fatores sociais, individuais e culturais prevalentes na população. O conhecimento do padrão de utilização desses serviços se torna essencial, para que as respostas a essas demandas reflitam decisões equânimes e efetivas em relação aos custos, uma vez que esse padrão oferece insumos durante o processo de alocação e geração de recursos.

Grandes variações têm sido documentadas entre áreas geográficas, nos aspectos de prática médica, tais como taxas de cirurgia e hospitalização, tempo de internação hospitalar, ou mesmo prescrição de medicamentos (Wennberg et al., 1984; Roos, 1984; Eisenberg, 1985; Roos e Roos, 1994). Uma possível explicação para essa ampla variação é o elevado grau de incerteza sobre a base científica da prática clínica (Wennberg, 1985), em que, além do estado de saúde do paciente, os custos exercem um papel importante na definição do padrão de consumo, resultando muitas vezes em uso desnecessário de certos procedimentos. A falta de consenso neste campo tem gerado um grande número de estudos, cujo principal objetivo é a identificação de fatores associados com a utilização de serviços de saúde (Andersen, 1968; Wennberg, 1973; McPherson et al., 1982; Hulka e Wheat, 1985; Phillips et al., 1998).

$\mathrm{O}$ acesso tem sido considerado um elemento de suma importância na utilização de serviços de saúde. Nesse sentido, a dinâmica de utilização de tais serviços tem sido avaliada a partir da sua disponibilidade, organização e mecanismos de financiamento, que atuam como elementos indutores de sua oferta (Eisenberg, 1985; Hulka e Wheat, 1985).

O padrão de utilização também tem sido focalizado a partir da demanda por serviços de saúde, voltando-se para as características demográficas e, principalmente, para o perfil de necessidades individuais (Hulka e Wheat, 1985; Himes e Rutrough, 1994).

Do ponto de vista da unidade de análise, esses estudos diferem quanto à incorporação ou não do mercado local hospitalar (Wennberg, 1985). Contudo, no âmbito da metodologia implementada, há uma clara predominância no emprego de modelos de regressão para identificação de fatores associados com o consumo de serviços de saúde. Neste estudo, as diferenças na utilização de tais serviços são analisadas a partir da identificação de perfis de consumo, elaborados através da implementação de técnicas baseadas na teoria de conjuntos difusos. Essa técnica assume que indivíduos podem apresentar características pertinentes a mais de um perfil, quantificando o grau de aproximação do conjunto de suas características àquelas dos perfis.

\section{Material e métodos}

\section{O marco de referência}

Andersen (1968) fez uma revisão ampla dos modelos teóricos de utilização de serviços, o que resultou num modelo teórico, no qual tanto os fatores individuais, quanto os hospitalares podem ser incorporados. Esse modelo, que serve de marco de referência neste estudo, assume que os principais fatores do perfil de consumo de saúde são agrupados em três dimensões: a) de capacitação; b) de necessidade e c) de predisposição.

a) Os fatores de capacitação referem-se à capacidade de um indivíduo procurar e receber serviços de saúde. Eles estão diretamente ligados, por um lado, às condições econômicas individuais e familiares e, por outro, à oferta de serviços na comunidade onde o indivíduo reside. Esses fatores incluem renda, planos de saúde, suporte familiar, disponibilidade, proximidade e quantidade de serviços ofertados (Andersen, 1995).

b) Os fatores de necessidade referem-se tanto às percepções subjetivas das pessoas acerca de sua saúde, quanto ao estado de saúde objetivo dos indivíduos. Hulka e Wheat (1985) ressaltam que o perfil de necessidades individuais constitui-se no determinante mais importante do padrão de consumo de serviços. Pinheiro e Travassos (1999) mostram que a morbidade referida foi o determinante mais expressivo da utilização de serviços de saúde entre os idosos do Rio de janeiro.

c) Os fatores de predisposição são aqueles relativos às características individuais que podem aumentar a chance de uso de serviços de saúde (Himes e Rutrough, 1994). Eles se referem ao conjunto de variáveis sociodemográficas e familiares como idade, sexo, nível de escolaridade e raça.

\section{Os dados}

Os dados a serem analisados são aqueles coletados pela Pesquisa Nacional por Amostras de Domicílio (PNAD) de 1998, no Suplemento Especial sobre Saúde. As variáveis selecionadas, representando os fatores de cada dimensão descrita no marco conceitual, são: 
a) De capacitação: Unidade da Federação e situação do domicílio de residência, tomadas, neste estudo, como proxy de oferta de serviços de saúde e proximidade a eles; o total de pessoas residentes no domicílio, tomado como indicativo de maior ou menor suporte familiar (Dickerson, 1998; Lo \& McLean, 1999, Glanz et al., 1999), fator fortemente associado ao consumo de saúde, principalmente, entre os idosos; a condição econômica, representada por duas variáveis: a renda per capita familiar e o número de bens de consumo do domicílio; e, finalmente, a posse de um plano de saúde, tomada como indicativo do grau de capacidade de consumo de saúde.

b) De necessidade: auto-avaliação do estado de saúde; freqüências de doenças crônicas e de "outras doenças" auto-referidas; condição de restrição de atividades habituais, por motivo de doença e escalas de limitações de atividades físicas.

c) De predisposição: posição do indivíduo em relação ao chefe do domicílio; condição (da) e posição na ocupação; anos de estudo; faixa de idade; sexo; e cor da pele ou raça.

O conjunto de variáveis que representam o consumo de saúde se relaciona com: procura habitual de serviços de saúde; procura de médicos no último ano e nas duas últimas semanas; gastos individuais com saúde; e freqüência e motivo da internação hospitalar. A relação das variáveis e suas respectivas categorias encontram-se no Anexo 1.

Do total da amostra, é excluída toda a região Norte, porque a PNAD não pesquisa a área rural dessa região. Além disso, são excluídas, também, as pessoas abaixo de 15 anos de idade, porque a escala de limitações de atividades físicas foi aplicada somente a pessoas acima de 14 anos. Ao final do processo, a amostra em estudo é composta por 187.364 pessoas.

\section{Metodologia de análise}

Para o delineamento de perfis de consumo de serviços de saúde, usa-se o método Grade of Membership, GoM (Woodbury et al., 1978; Manton et al., 1994; Lamb, 1996; Portrait et al., 1999, 2001; Cassidy et al., 2001), que se utiliza da teoria de conjuntos difusos. A aplicação dessa metodologia, para delineamento de perfis, considera, segundo Sawyer et al. (2000), que:

a) A associação, não observada, entre as categorias das variáveis no modelo, delineia dois ou mais perfis, bem determinados, que se denominam perfis extremos;

b) Esses perfis extremos correspondem a conjuntos fechados, clássicos e com todas as suas propriedades; a cada indivíduo são atribuídos graus de sua pertinência aos perfis extremos. Assim, se um indivíduo possui todas as características de um dos perfis extremos, o grau de pertinência a esse perfil será de $100 \%$ e, conseqüentemente, zero aos demais. Quanto mais esse indivíduo se aproximar do perfil extremo, maior será o seu grau, em relação a esse perfil, e menor em relação aos demais. Não é raro ter-se indivíduos que estejam eqüidistantes a todos os perfis extremos e, portanto, não possuindo características que os aproximem de nenhum deles; c) Os graus de pertinência dos indivíduos constituem um conjunto nebuloso. Nesse sentido, quanto maior o número de variáveis melhor o conjunto fica definido;

d) O método estima os seus parâmetros por processos iterativos, e, portanto, quanto menor o tamanho da amostra, menor o seu tempo de convergência.

Os itens (c) e (d) conferem ao método, dentro de limites plausíveis, a vantajosa propriedade de melhores resultados, quanto menor o tamanho da amostra e quanto maior o número de variáveis. Além disso, como o grau de pertinência de cada indivíduo é dado pela conjunção, neste indivíduo, de todas as categorias das variáveis do modelo, o método releva, e de forma muito simples, a heterogeneidade presente na amostra.

O GoM estima a probabilidade de uma categoria $l$, de uma variável $j$, pertencer ao perfil extremo $k, \lambda_{k j l}$, simultaneamente, ao grau de pertinência, $g_{i k}$, de um indivíduo $i$ a um perfil extremo $k$. Portanto, a interpretação dos parâmetros pode ser feita de forma iterativa: os primeiros $\left(\boldsymbol{\lambda}_{k j l}\right)$ caracterizam os perfis extremos, ou seja, medem a probabilidade que tenha uma pessoa, com grau de pertinência total ao perfil $k$, dada a resposta na categoria $l$, da variável $j$, enquanto os últimos $\left(g_{i k}\right)$ representam o grau de proximidade que cada indivíduo tem ao perfil extremo $k$. Essa proximidade é medida por meio da comparação das possíveis combinações de respostas nas categorias $l$ do indivíduo com o conjunto de respostas configuradas no perfil extremo.

Para o presente trabalho, considera-se um modelo de dois níveis: o primeiro estima os valores de $\lambda_{k j}$, para as variáveis representativas dos fatores de capacitação, de necessidade e de predisposição, que a partir deste ponto serão denominados fatores associados ao consumo de serviços, permitindo caracterizar os perfis extremos desses fatores. Nesse nível, estima-se, tam- 
bém, o grau de pertinência $g_{i k}$ de cada pessoa da amostra a esses perfis, quantificando a maior ou menor proximidade das características desta pessoa às características dos perfis extremos. $\mathrm{O}$ segundo nível fixa os valores de $g_{i k}$ obtidos no primeiro nível e ajusta o modelo com a inclusão das variáveis referentes ao consumo de serviços médicos, denominadas variáveis externas ao modelo, para estimativa de novos $\lambda_{k j l}$. Essas novas estimativas são empregadas para se definirem as características de perfis extremos de consumo, em conseqüência dos perfis extremos de fatores associados e da heterogeneidade dos indivíduos em relação a estes últimos perfis.

\section{Resultados e discussões}

\section{Os perfis extremos}

O Anexo 1 apresenta as variáveis agrupadas segundo os fatores, além de suas distribuições marginais de freqüências absolutas e relativas. Apresenta, também, os valores de $\lambda_{k j l}$ em cada perfil extremo que, comparados com a freqüência marginal correspondente, permitem avaliar a sua dominância no perfil. Conforme pode ser visto, quatro perfis foram gerados. Ainda que esses perfis possam ser determinados com base em critérios técnicos (Manton et al., 1994), neste estudo eles foram definidos a partir da avaliação da "significância substantiva" dos perfis extremos, ou seja, a cada perfil novo criado, procurou-se verificar se as mudanças observadas podiam ser justificadas do ponto de vista teórico. Considerou-se que uma categoria $l$, de uma variável $j$, seria característica de um perfil $\mathrm{k}$, se a relação entre $\lambda_{k j l}$ e a freqüência marginal (RLFM) fosse igual ou maior do que 1,20. O valor da RLFM é arbitrário e sua escolha depende do grau de heterogeneidade que se queira apreender da amostra. Quanto maior o seu valor, mais restritivo será o processo de inclusão de categorias das variáveis a um determinado perfil. O valor escolhido é menor do que o encontrado em outros estudos (Berkman et al., 1989; Machado, 1997), contudo, parece que captou bem as características dominantes dos perfis extremos. Os valores que preenchem a condição estabelecida foram destacados em negrito e itálico.

A seguir apresentam-se as características de cada perfil extremo, de acordo com o critério mencionado. A caracterização é feita, de forma pontual, para cada grupo de fatores associados e para as variáveis de consumo de serviços; ao final de cada grupo, interpreta-se o conjunto das categorias selecionadas, para uma definição do perfil extremo. Para facilitar a leitura, os tempos de referência das variáveis de consumo de serviços de saúde serão mencionados apenas uma vez, na primeira ocorrência.

As pessoas com pertinência total ao Perfil Extremo 1 têm, predominantemente, as seguintes características:

a) Fatores de Capacitação: residências em UF das regiões Nordeste e Centro-Oeste; em área rural; em domicílios com mais de quatro pessoas; com dois a seis bens de consumo; com renda per capita mensal familiar de até dois salários-mínimos e não possuem planos de saúde; b) Fatores de Necessidades: consideram o seu estado de saúde bom; nas últimas duas semanas, não estiveram acamados; não têm doenças crônicas; e não apresentam dificuldade para qualquer atividade física pesquisada;

c) Fatores de Predisposição: são filhos em relação ao chefe de domicílio; do sexo masculino; desocupados ou trabalhador por conta própria; até oito anos completos de estudos; na faixa de idade de 15 a 49 anos; e de cor parda ou preta; d) Consumo de Serviços Médicos: não efetuaram gastos com saúde nos últimos três meses (30 dias para medicamento); não procuram um serviço de saúde fixo quando têm problemas de saúde, quando o fazem, procuram a farmácia, posto de saúde ou ambulatório de empresa ou sindicato; não consultaram médico no ano; não costumam ir ao dentista; nas duas últimas semanas, procuraram serviços de saúde para reabilitação; por este mesmo motivo procuraram os serviços, mais de três vezes, em consultório odontológico e hospital.

Esse perfil extremo descreve o comportamento de jovens, do sexo masculino, de estrato social baixo, cujo estado de saúde, pela autoavaliação e pelos indicadores de doenças e limitações de atividades, pode ser considerado bom. O comportamento habitual de procurar farmácia, quando tem problemas de saúde, e a ausência de consultas médicas contrastam com o fato de que, nas duas últimas semanas, procurou mais de três vezes consultório odontológico ou hospital para reabilitação. Esse padrão pode indicar que essas pessoas sejam consumidoras ocasionais de serviços de saúde, por motivos outros que a doença. $\mathrm{Na}$ amostra, 18.573 pessoas têm grau de pertinência total a esse perfil, ou seja, 9,9\% das pessoas acima de 15 anos apresentam todas as características do perfil. 
As pessoas, com pertinência total ao Perfil Extremo 2 têm, predominantemente, as seguintes características:

a) Fatores de Capacitação: residentes no Piauí, em UF da região Sudeste e Sul e no Distrito Federal; em domicílios com dois a três moradores; com mais de sete bens de consumo; com renda per capita acima de três salários-mínimos e possuidoras de planos de saúde;

b) Fatores de Necessidade: elas se dividem entre as que consideram o seu estado de saúde bom e as que o consideram ruim; não estiveram acamadas nas duas últimas semanas; não têm doenças crônicas e não apresentam dificuldade para qualquer atividade física pesquisada;

c) Fatores de Predisposição: são do sexo feminino; são empregadoras ou trabalhadoras com carteira; têm mais de 9 anos de estudo; de cor amarela ou indígena ou branca;

d) Consumo de Serviços Médicos: efetuaram gastos com saúde acima de $\mathrm{R} \$ 20,00$; procuram consultório médico particular, ambulatório ou consultório de clínica quando têm problemas de saúde; procuraram médico e dentista duas vezes durante o ano e nas duas últimas duas semanas; procuraram consultório médico particular, dentista e hospital para exames e partos (categoria outros).

Esse Perfil Extremo corresponde às mulheres brancas, de estrato socioeconômico alto, e saudáveis. Entretanto, uma parte delas considera o seu estado de saúde ruim. Elas têm um alto consumo de serviços de saúde particulares e hospitalares. O número de pessoas com pertinência total a esse perfil é de 14.049 , representando 7,5\% da amostra.

A descrição das pessoas do Perfil Extremo 3 é como se segue:

a) Fatores de Capacitação: residentes em alguns estados do Nordeste; na área rural; em domicílios unipessoais ou de dois a três moradores; com cinco a seis bens de consumo e renda per capita de um quarto a um salário-mínimo; b) Fatores de Necessidade: consideram o seu estado de saúde regular ou ruim; estiveram acamadas, nas duas últimas semanas, por motivo de doença ou por causas externas ou outro motivo; possuem de duas a cinco doenças crônicas; uma ou duas das outras doenças e com relação ao exercício de atividade física, são pessoas cuja limitação de atividades variam de pequena dificuldade até não conseguir desempenhar todos os itens pesquisados;

c) Fatores de Predisposição: as suas relações com o chefe do domicílio são de cônjuge, outro parente/agregado ou mesmo empregado doméstico; não trabalham ou trabalham por conta própria; até quatro anos de escolaridade, incluindo aquelas com nenhuma escolaridade; na faixa de idade acima dos 50 anos; de cor amarela ou indígena;

d) Consumo de Serviços Médicos: realizaram algum gasto com saúde; consultam ambulatório de empresa ou sindicato quando têm problemas de saúde; consultaram médico mais de duas vezes, no último ano; não vão a dentistas; procuraram serviços de saúde, nas duas semanas, mais de uma vez, para exames ou prevenção, tratamento ou reabilitação ou doença, em posto de saúde, emergência, hospital, laboratório de exames e atendimento domiciliar; estiveram internadas por motivos clínicos, cirurgia ou tratamento psiquiátrico.

Esse perfil corresponde àquelas pessoas do sexo feminino, de baixa renda e escolaridade, na terceira idade, que moram sós ou em domicílios pequenos. Consideram o seu estado de saúde ruim e têm estado de saúde ruim, o que leva a um alto consumo de serviços de saúde, incluindo exames, consultas de rotina e prevenção. O número de pessoas com pertinência total a esse perfil corresponde a $1,4 \%$ da amostra $(2.682$ pessoas).

O quarto perfil define-se pelas seguintes características dominantes, segundo os fatores:

a) Fatores de Capacitação: residentes do Nordeste e Centro-Oeste; moram sós; têm três bens de consumo; com renda per capita não muita bem definida, concentrada nas categorias menos de $1 / 4$, de dois a três e de três a cinco salários-mínimos; moram sós e possuem planos de saúde;

b) Fatores de Necessidade: consideram o seu estado de saúde regular ou ruim; estiveram acamadas, nas duas últimas semanas por mais de dois dias; por motivos de doenças, por causas externas e por outras causas; referiram de duas a seis doenças crônicas e de uma a três das outras doenças; com problemas de limitação de atividades físicas em todos os itens pesquisados, que variaram de pequena dificuldade até incapacidade de realizar as atividades físicas;

c) Fatores de Predisposição: a relação com o chefe de família se concentra em "outro parente" ou "agregado", trabalham por conta própria; sem instrução ou até quatro anos de estudos; em faixa etária de mais de 50 anos de idade; e cor amarela ou indígena;

d) Os indivíduos desse perfil apresentam o mais alto consumo de serviços de saúde, tanto em relação a gastos quanto em relação à fre- 
qüência da procura, ressaltando-se a diversidade de motivos dados para tal procura. Os serviços mais demandados são: farmácia, ambulatório ou consultório de clínica e pronto-socorro.

Esse é o grupo de idosos que moram sós, de baixa renda e escolaridade, com estado de saúde ruim e altíssima demanda de serviços de saúde, correspondendo a $0,22 \%$ da amostra (410 pessoas).

Ao se compararem indivíduos desse Perfil com aqueles do Perfil 3, observa-se que ambos possuem estado de saúde ruim e se referem a idosos. A diferença é que no Perfil 3 predominam as mulheres e pessoas de menor renda, enquanto no Perfil 4 predominam as pessoas que moram sozinhas, mais idosas, com nível de consumo muito mais alto e estrutura mais diversificada.

\section{Os perfis de consumo segundo características dominantes}

Há que se lembrar que as descrições acima se referem a perfis extremos, os quais podem incluir algumas características relativamente raras na população, como residir em áreas rurais; haver predominância de residência nos estados do Nordeste; e ser da cor/raça amarela e indígena. Note-se que apenas $19 \%$ da população pertence a um único perfil e, à medida que os indivíduos vão se afastando de um perfil extremo, passa a perder algumas das características desse perfil e a assimilar as de outro. Nesse sentido, a classificação da população será feita através do conceito de predominância das características de um perfil.

A predominância das características de um perfil será definida por expressões que descrevam a combinação dos graus de pertinências dos indivíduos. Para facilitar, são apresentados exemplos das expressões de características predominantes ou mistas dos Perfis 1 e 2. Uma pessoa é classificada com características predominantes do Perfil 1 se:

a) $g_{i 1} \geq 0,70$

b) $\left(0,60 \leq g_{i 1}<0,70\right) \cap\left\{\begin{array}{l}g_{i 2}+g_{i 3} \leq 0,30 \\ g_{i 2}+g_{i 3} \leq 0,30 \\ g_{i 3}+g_{i 4} \leq 0,30\end{array}\right.$

A expressão (a) se refere à predominância de nível um (P1.1), em que a pessoa tem pelo menos 70\% das características do Perfil Extremo 1 . O caso (b) trata de predominância de nível dois $(P 2.1)$ em que uma pessoa tem de 60 a
$70 \%$ das características do Perfil e a soma das pertinências de quaisquer outros dois perfis não ultrapasse $30 \%$.

Os casos mistos são definidos como:

a) $\left(0,60 \leq g_{i 1} \leq 0,70\right) \cap\left(0,30 \leq g_{i 2} \leq 0,40\right)$.

b) $\left(0,40 \leq g_{i 1} \leq 0,50\right) \cap\left(0,40 \leq g_{i 2} \leq 0,50\right)$.

O caso (a) trata de pessoas com características dos Perfis1 e 2, sendo que as do primeiro predominam àquelas do segundo (MP12). $\mathrm{O}$ caso (b) agrupa as pessoas com características compartilhadas do Perfil Extremo 1 e do 2, sem uma clara predominância de um ou de outro (MSP12).

A tabela 1 apresenta os perfis definidos, como descritos acima, segundo a freqüência absoluta e relativa, assim como a descrição dos perfis extremos para melhor entendimento dos resultados.

As pessoas com características predominantes de níveis 1 e 2, dos Perfis 1 e 2, são as mais freqüentes $(31,8 \%$ do primeiro e $23,6 \%$ do segundo), enquanto aquelas com predominância do terceiro perfil somam $9,1 \%$ e as com predominância do quarto perfil somam $1 \%$ do total das 187.264 pessoas da amostra.

Os Anexos 2.1 a 2.4 mostram as principais características das pessoas em cada um dos perfis em termos de percentuais e médias das categorias das variáveis em cada fator. Nota-se que as variáveis "região de residência", "situação do domicílio" e "número de bens de consumo" perdem a capacidade de especificar os perfis definidos.

Os perfis $P 1.1$ e P2.1 aderem ao Perfil Extremo 1 , uma vez que se trata de pessoas predominantemente jovens, do sexo masculino, de baixa renda, escolaridade baixa ou média, de cor parda ou negra, que consideram a sua saúde boa, reportam poucas doenças crônicas e com baixo consumo de serviços de saúde. A mesma aderência é verificada nos demais perfis de predominância, com os seus respectivos perfis extremos. Assim, P1.2 e P2.2 se referem, predominantemente, a mulheres jovens, de alto nível de escolaridade e renda, brancas, que consideram sua saúde como sendo boa, reportam poucas doenças e apresentam elevado consumo de saúde. Enquanto P1.3 e P2.3 aglutinam mulheres de 60 a 70 anos, baixas escolaridade e renda, que moram sós, que consideram a sua saúde ruim, reportam presença de morbidades crônicas e limitações de atividades físicas nos itens pesquisados, com exceção do item referen- 
Tabela 1

Freqüência absoluta e relativa dos residentes fora da região Norte e acima de 14 anos de idade, segundo tipologia de predominância de características dos perfis extremos. Pesquisa Nacional por Amostra de Domicílios, IBGE, 1998.

\begin{tabular}{|c|c|c|c|}
\hline \multirow[t]{2}{*}{ Descrição do Perfil Extremo } & \multirow{2}{*}{$\begin{array}{l}\text { Perfis com } \\
\text { predominância }^{1}\end{array}$} & \multicolumn{2}{|c|}{ Freqüência } \\
\hline & & Absoluta & Relativa \\
\hline \multirow{6}{*}{$\begin{array}{l}\text { Perfil 1: "homens, jovens, pardos ou negros, } \\
\text { estrato socioeconômico médio-baixo, saudáveis } \\
\text { e consumidores ocasionais" }\end{array}$} & P1.1 & 51.967 & 0.278 \\
\hline & P2.1 & 7.559 & 0.040 \\
\hline & MP12 & 16.682 & 0.089 \\
\hline & MP13 & 5.837 & 0.031 \\
\hline & MP14 & 72 & 0.000 \\
\hline & Subtotal & 82.117 & 0.439 \\
\hline \multirow{6}{*}{$\begin{array}{l}\text { Perfil 2: "mulheres, brancas, estrato } \\
\text { socioeconômico alto, saudáveis, alto consumo" }\end{array}$} & $\mathrm{P} 1.2$ & 39.369 & 0.210 \\
\hline & P2.2 & 4.895 & 0.026 \\
\hline & MP21 & 17.071 & 0.091 \\
\hline & MP23 & 3.687 & 0.020 \\
\hline & MP24 & 26 & 0.000 \\
\hline & Subtotal & 65.048 & 0.347 \\
\hline \multirow{6}{*}{$\begin{array}{l}\text { Perfil 3: "mulheres, estrato socioeconômico baixo, } \\
\text { terceira-idade, auto-avaliam estado de saúde como } \\
\text { ruim, saúde ruim, alto consumo" }\end{array}$} & P1.3 & 13.670 & 0.073 \\
\hline & P2.3 & 3.313 & 0.018 \\
\hline & MP31 & 4.422 & 0.024 \\
\hline & MP32 & 3.355 & 0.018 \\
\hline & MP34 & 184 & 0.001 \\
\hline & Subtotal & 24.944 & 0.133 \\
\hline \multirow{15}{*}{$\begin{array}{l}\text { Perfil 4: "idosos, moram sós, estrato socioeconômico } \\
\text { não definido, estado de saúde ruim e altíssimo consumo" }\end{array}$} & P1.4 & 1.743 & 0.009 \\
\hline & $\mathrm{P} 2.4$ & 236 & 0.001 \\
\hline & MP41 & 191 & 0.001 \\
\hline & MP42 & 181 & 0.001 \\
\hline & MP43 & 179 & 0.001 \\
\hline & Subtotal & 2.530 & 0.014 \\
\hline & MSP12 & 5.407 & 0.029 \\
\hline & MSP13 & 2.782 & 0.015 \\
\hline & MSP14 & 25 & 0.000 \\
\hline & MSP23 & 2.369 & 0.013 \\
\hline & MSP24 & 16 & 0.000 \\
\hline & MSP34 & 30 & 0.000 \\
\hline & Subtotal & 10.629 & 0.057 \\
\hline & Não definido & 1.996 & 0.011 \\
\hline & TOTAL & 187.264 & 1.000 \\
\hline
\end{tabular}

1 P1.X: Predominância de Nível 1 (70\% ou mais da característica do Perfil Extremo X); P2.X: Predominância de Nível 2 (60 a 69\% das características do Perfil X e soma dos graus de pertinência dos demais perfis não excedem 30\%); MPXY: Misto com predominância de X sobre Y; MSPXY: Misto sem predominância.

te a "dificuldade para alimentar-se, tomar banho, etc..... Além disso, apresentam elevado gasto com saúde e consumo de serviços. Os últimos grupos, $P 1.4$ e P2.4, diferem dos anteriores por serem constituídos de pessoas extremamente idosas e com severas limitações de atividades físicas. Nos últimos grupos, ou seja, naqueles com predominância de características do Perfil Extremo 3 e 4, a cor da pele amarela ou raça indígena desaparecem como atributo marcante.
O exame das características dos perfis mistos revela que:

a) A combinação do Perfil 1 com os demais, seja ele predominante ou não, aumenta a proporção de pessoas do sexo masculino, rejuvenesce o grupo, diminui a escolaridade e renda, e aumenta a proporção de pessoas de cor parda ou negra;

b) A combinação do Perfil 2 com os demais aumenta a escolaridade, a renda, a proporção 
de brancos, a proporção de mulheres e a presença de plano de saúde;

c) A combinação do Perfil 3 com os demais diminui a escolaridade e a renda, envelhece o grupo, aumenta a proporção de pessoas do sexo feminino, aumenta a proporção de pessoas que moram sós, piora o estado de saúde, tanto na autopercepção quanto nas morbidades referidas e limitação das atividades físicas, e aumenta o consumo de saúde;

d) A combinação do Perfil 4 com os demais produz resultados semelhantes ao do Perfil 3 , mas com efeitos mais exacerbados.

Todos os perfis incluem, com maior ou menor necessidade, consumidores habituais de serviço de saúde, à exceção dos $P 1.1$ e $P 2$., que são consumidores ocasionais. Considerando que a pesquisa domiciliar revelou que $24,0 \%$ da amostra procuravam consultórios particulares e ambulatórios ou consultórios de clínica e que $26,2 \%$ procuravam posto ou centro de saúde, pode-se, a título de exercício, estimar uma demanda, qualificada, de serviços públicos e privados no país.

A tipologia acima descrita permite, por sua vez, classificar a demanda por serviços de saúde no país, segundo os níveis dos fatores associados, ou seja, capacitantes, de necessidade e predisponentes. Considera-se que um grupo tenha: 1) alta capacidade de consumo de saúde, se predominarem os indivíduos de alta renda, possuírem plano de saúde e residirem em domicílio com mais de quatro pessoas; 2) alta necessidade por serviços de saúde, se os indivíduos considerarem a sua saúde ruim, além de mencionarem, em média, mais de uma doença crônica e apresentar mais de $15 \%$ de pessoas que não conseguem ou têm grande dificuldade em exercer alguma das atividades físicas pesquisadas; 3 ) alta predisposição para consumo de saúde, se possuírem alta escolaridade e alta proporção de pessoas acima de 60 anos e do sexo feminino. Como muitas vezes alta escolaridade não é compatível com pessoas idosas, o critério idade prevalece para se definir a alta predisposição.

A tabela 2 apresenta quais os perfis de demanda que preenchem o cruzamento dos três fatores. Mostra, também, o número de pessoas em cada cruzamento, a sua freqüência relativa, e qual seria o número esperado no ano 2000, se estas condições prevalecessem.

A alta capacidade de demanda por saúde dimensiona o potencial de procura por serviços privados ou de firmas, que era estimada, no ano 2000, em 51.715.667 pessoas. Há que se inter- pretar essa estimativa como a demanda máxima potencial, uma vez que ela foi feita com base na freqüência de atributos predominantes. Dentre esses, o percentual com alta demanda de serviço especializado para doenças crônicas e limitações de atividades físicas são, relativamente, pequenas. Entretanto, a necessidade por serviços de saúde é baseada em número de morbidades e limitações específicas referidas, sem cobrir todo o universo de afecções possíveis e, portanto, dos serviços especializados requeridos.

Com a mesma ressalva feita com relação às estimativas acima citadas, a demanda máxima por serviços públicos chega a $53,2 \%$ da população, no ano de 2000, isto é, 57.553 .385 pessoas. Especial atenção deve ser dada ao grupo de alta necessidade e predisposição, mas baixa capacidade para o consumo, não apenas pela necessidade de serviços especializados, como também pela presença de indivíduos em idades bastante avançadas e pela presença de idosos que moram sós. Esse conjunto representa $14,3 \%$ da população de referência.

Ressalta-se, ainda, que, cerca de $35 \%$ da população é classificada no grupo, com baixa capacidade, necessidade e predisposição. Esses grupos são caracterizados pelo baixo consumo, por considerarem sua saúde boa e não reportarem doenças crônicas ou limitações de atividades. Se, por um lado, este contingente diminui a real demanda por serviços públicos, por outro, não se pode aferir se as ausências de morbidades e limitações são devidas, justamente, à baixa procura de serviços de saúde ou se esta é devida àquelas. Caso se mantenham as condições de baixa capacitação, este grupo poderá, potencialmente, num futuro próximo, mais do que duplicar o contingente de baixa capacidade, alta necessidade e alta predisposição por serviços, uma vez que o aumento da longevidade e as difíceis condições de ascensão socioeconômica intrageracional são fatos reais no país.

Neste cenário, a demanda máxima de adultos por serviços privados e conveniados em planos de saúde não ultrapassará os $50 \%$ da população brasileira. Os serviços públicos voltados à população de baixa renda deverão se preparar para atendimento especializado da população idosa, pois é no grupo de idosos de baixa renda que se concentram as pessoas de alta morbidade e de graves limitações de atividades físicas, que, se não acompanhado por um trabalho preventivo das populações jovens, poderá atingir num futuro próximo dimensões surpreendentemente altas. 
Tabela 2

Perfis de consumo de serviços de saúde no Brasil,1 de pessoas acima de 14 anos, segundo os níveis dos fatores associados, número de pessoas pertencente a esses perfis e número esperado em 2000.

\begin{tabular}{|c|c|c|c|c|c|c|}
\hline Capacitante & $\begin{array}{l}\text { Fatores } \\
\text { Necessidade }\end{array}$ & Predisposição & Perfis de consumo & $\begin{array}{l}\text { Pessoas na } \\
\text { amostra }\end{array}$ & $\begin{array}{l}\text { Freqüência } \\
\text { relativa }\end{array}$ & $\begin{array}{l}\text { Número esperado } \\
\text { em cada grupo, } \\
\text { no ano de } 2000\end{array}$ \\
\hline \multirow[t]{4}{*}{ Altos } & Altos & Altos & $\begin{array}{l}\text { MP23, MP24,MP32, } \\
\text { MP42,MSP23,MSP24,MSP34 }\end{array}$ & 9.664 & 0,052 & 5.699 .983 \\
\hline & Baixos & & & & - & - \\
\hline & Baixos & Altos & $\mathrm{P} 1.2, \mathrm{P} 2.2$ & 44.264 & 0,236 & 26.107 .621 \\
\hline & & Baixos & MP12, MP21 & 33.753 & 0,180 & 19.908.063 \\
\hline \multirow[t]{5}{*}{ Baixos } & Altos & Altos & $\begin{array}{l}\text { P1.3, P2.3, P1.4, P2.4, MP31, MP41, } \\
\text { MP34.MP43,MSP13,MSP14 }\end{array}$ & 26.745 & 0,143 & 15.774 .632 \\
\hline & & Baixos & MP13, MP14 & 5.909 & 0,032 & 3.485 .223 \\
\hline & Baixos & Altos & MSP12 & 5.407 & 0,029 & 3.189 .136 \\
\hline & & Baixos & $\mathrm{P} 1.1, \mathrm{P} 2.1$ & 59.526 & 0,318 & 35.109 .394 \\
\hline & & & Não definido & 1.996 & 0,011 & 1.177 .273 \\
\hline \multicolumn{4}{|l|}{ Total } & 187.264 & 1,000 & \\
\hline \multicolumn{6}{|c|}{ População do Brasil, sem a região Norte e acima de 14 anos } & 110.451 .325 \\
\hline
\end{tabular}

Fonte: Dados elaborados a partir da PNAD/1998 e Censo Demográfico de 2000.

${ }^{1}$ Excluindo a região Norte.

\section{Conclusão}

Neste estudo, a técnica do Grade of Membership (GoM) foi utilizada para a geração de perfis de utilização de serviços de saúde, tendo por base as informações do Suplemento Saúde da PNAD/98. O modelo teórico de utilização de serviços de saúde proposto por Andersen (1995) serviu como marco de referência da análise. Segundo o modelo, os principais fatores de consumo de serviços de saúde são agrupados em três dimensões: a) de capacitação; b) de necessidade e c) de predisposição.

Ao contrário da aplicação convencional do GoM, em que os perfis são criados a partir da inclusão de todas as variáveis simultaneamente, esta análise foi implementada em dois estágios. No primeiro, quatro perfis foram gerados, baseados em variáveis associadas ao consumo. No segundo estágio, os perfis são pré-fixados e os parâmetros de associação e estrutura são reestimados para as demais variáveis representativas do consumo.

Essa metodologia permitiu que fossem feitas estimativas de demanda por serviço de saúde, segundo níveis altos e baixos de capacitação, necessidade e predisposição para o consumo. Essa análise ressalta a necessidade de atenção especial ao grupo marcado por alta necessidade, alta predisposição e baixa capacidade de consumo, que corresponde a aproximadamente $14 \%$ da população acima de 14 anos de idade no país, excluída a região Norte. Esse grupo é composto, predominantemente, por pessoas idosas, que moram sozinhas, com alta necessidade de serviços especializados. Cabe ainda ressaltar o enorme contingente de indivíduos (35.109.394) com baixa capacitação, necessidade e predisposição para o consumo. Esses indivíduos têm baixa necessidade, pois se auto-avaliam em bom estado de saúde e não possuem doenças crônicas, nem limitações de atividades, o que pode suscitar a dúvida se a ausência de morbidades é devida ao baixo nível de capacitação para o consumo deste grupo. De qualquer forma, esse grupo constitui os potenciais alvos de medidas preventivas. Devido à importância dos resultados encontrados, estudos futuros devem aprofundar a análise, de forma a entender melhor a dinâmica de utilização de serviços. 


\section{Referências bibliográficas}

Andersen RM 1968. A behavioral model of families' use of health services. HSA Studies, University of Chicago Research Series No. 25

Andersen RM 1995. Revisiting the behavioral model and access to medical care: does it matter? Journal of Health and Social B 36(1):1-10.

Berkman L et al. 1989. Black/white differences in health status among elderly. Demography 26(4): 661-678.

Cassidy F, Pieper CF, Carrol BJ 2001. Subtypes of mania determined by Grade of Membership Analysis. Neuropsychopharmacology 25(3):373-383.

Dickerson SS 1998. Help seeking in spouses of cardiac patients. Clinical Nursing Research 7(1):6-28.

Eisenberg JM 1985. The state of research about physicians' practice patterns Medical Care 23(5); 461-481.

Glanz K, Grove J, Lerman C, Gotay C, Le Marchand L 1999. Correlates of intentions to obtain genetic counselling and colorectal cancer gene testing among at-risk relatives from three ethnic groups. Cancer Epidemiology Biomarkers and Prevention 8(4 Pt 2):329-236.

Himes, CL \& Rutrough, TS 1994. Differences in the use of health services by metropolitan and nonmetropolitan elderly. The Journal of Rural Health 10(2):80-88.

Hulka BS \& Wheat JR 1985. Patterns of utilization. Medical Care 23(5):438-460.

Lamb VL 1996. A cross-national comparison of quality of life factors associated with partners of elderly disablement. Social Science and Medicine 42(3): 363-367

Lo R \& Maclean D 1999. Correlates of expected success at adherence to health regimen of people with IDDM. Journal of Advanced Nursing 30(2):418-424.

Machado JM 1997. Perfis de morbi-mortalidade infantil no estado de São Paulo, 1994: uma aplicação de Grade of Membership à análise de causas múltiplas de morte. Tese de mestrado apresentada ao Centro de Desenvolvimento e Planejamento Regional (Cedeplar/UFMG).

McPherson K et al. 1982. Small variations in the use of common surgical procedures: an international comparison of England and Norway. New England Journal of Medicine 307(21):1.310-1.314.

Manton KG, Woodbury MA \& Tolley, HD 1994. Statistical application using fuzzy sets. John Wiley \& Sons, Nova York.
Phillips KA et al. 1998. Understanding the context of health care utilization: assessing environmental and provider-related variables in the behavioral model of utilization. Health Services Research 33(3):571-596

Portrait F, Lindeboom M \& Deeg D 1999. Health and mortality of the elderly: the grade of membership method, classification and determination. Health Economics 8(5):441-457.

Portrait F, Lindeboom M \& Deeg D 2001. Life expectancies in specific health states: results from a joint model of health status and mortality of older persons. Demography 38(4): 525-536.

Pinheiro RS \& Travassos C 1999. Estudo da desigualdade na utilização de serviços de saúde por idosos em três regiões da cidade do Rio de Janeiro. Cadernos de Saúde Pública 15(3):487-496.

Roos, NP 1984. Hysterectomy: variation in rates across small areas and across physician's practices. American Journal of Public Health 74:327-335.

Roos, NP e Roos, LL 1994. Small area variations, practice style, and quality of care. In Braer ML \& Marmor TR (ed.). Why are some people healthy and others not? The determinants of health of populations. Aldine de Gruyter, Nova York.

Sawyer DO et al. 2000. Caracterização dos tipos de doadores de sangue em Belo Horizonte: heterogeneidade do homogêneo. Anais do XII Encontro de Estudos Populacionais. Caxambu MG.

Wennberg JE 1985. On patient need, equity, supplier-induced demand, and the need to assess the outcome of common. Medical Care 23(5):512-520.

Wennberg JE, McPherson K \& Caper, P 1984. Will payment based on Diagnosis-Related Groups control hospital costs? New England Journal of Medicine 311(5):295-300.

Woobury MA et al. 1978. Mathematical typology: a grade of membership technique for obtaining disease definition. Computers and Biomedical Research 11:277-298.

Artigo apresentado em 8/9/2002

Aprovado em 10/10/2002

Versão final apresentada em 5/11/2002 
Anexo 1

Estimativas de $\lambda_{k j l}$, por categorias das variáveis internas e externas;

freqüências marginais absolutas e relativas, Brasil,1 1998.

\begin{tabular}{|c|c|c|c|c|c|c|}
\hline \multirow[t]{2}{*}{ Fatores e variáveis } & \multicolumn{2}{|c|}{ Freqüência marginal } & \multicolumn{3}{|c|}{ Perfis extremos } & \multirow[b]{2}{*}{4} \\
\hline & Absoluta & Relativa & 1 & 2 & 3 & \\
\hline \multicolumn{7}{|l|}{ Capacitante } \\
\hline \multicolumn{7}{|l|}{ Unidade da Federação } \\
\hline Maranhão & 1.447 & 0,008 & 0,0013 & 0,0000 & 0,0000 & 0,1011 \\
\hline Piauí & 1.492 & 0,008 & 0,0113 & 0,0494 & 0,0219 & 0,0588 \\
\hline Ceará & 9.166 & 0,049 & 0,0720 & 0,0209 & 0,0573 & 0,0533 \\
\hline Rio Grande do Norte & 2.506 & 0,013 & 0,0200 & 0,0000 & 0,0376 & 0,0162 \\
\hline Paraíba & 2.942 & 0,016 & 0,0156 & 0,0065 & 0,0686 & 0,0398 \\
\hline Pernambuco & 12.893 & 0,069 & 0,0918 & 0,0340 & 0,0881 & 0,0474 \\
\hline Alagoas & 2.069 & 0,011 & 0,0180 & 0,0000 & 0,0153 & 0,0308 \\
\hline Sergipe & 2.484 & 0,013 & 0,0263 & 0,0000 & 0,0096 & 0,0183 \\
\hline Bahia & 14.284 & 0,076 & 0,1151 & 0,0354 & 0,0680 & 0,0586 \\
\hline Minas Gerais & 25.147 & 0,134 & 0,1558 & 0,1065 & 0,1184 & 0,0711 \\
\hline Espírito Santo & 3.711 & 0,020 & 0,0280 & 0,0092 & 0,0217 & 0,0636 \\
\hline Rio de Janeiro & 18.120 & 0,097 & 0,0733 & 0,1208 & 0,1003 & 0,0603 \\
\hline São Paulo & 29.900 & 0,160 & 0,0551 & 0,2484 & 0,1122 & 0,0717 \\
\hline Paraná & 13.534 & 0,072 & 0,0781 & 0,0737 & 0,0674 & 0,0517 \\
\hline Santa Catarina & 5.783 & 0,031 & 0,0258 & 0,0393 & 0,0298 & 0,0335 \\
\hline Rio Grande do Sul & 19.452 & 0,104 & 0,0851 & 0,1280 & 0,0977 & 0,0563 \\
\hline Mato Grosso do Sul & 3.829 & 0,020 & 0,0301 & 0,0115 & 0,0156 & 0,0383 \\
\hline Mato Grosso & 3.502 & 0,019 & 0,0305 & 0,0079 & 0,0129 & 0,0475 \\
\hline Goiás & 8.828 & 0,047 & 0,0668 & 0,0225 & 0,0560 & 0,0430 \\
\hline Distrito Federal & 6.175 & 0,033 & 0,0000 & 0,0860 & 0,0017 & 0,0388 \\
\hline \multicolumn{7}{|l|}{ Situação do domicílio } \\
\hline Urbana & 168.284 & 0,899 & 0,8681 & 0,9548 & 0,6162 & 0,9616 \\
\hline Rural & 18.980 & 0,101 & 0,1319 & 0,0452 & 0,3838 & 0,0384 \\
\hline \multicolumn{7}{|c|}{ Total de moradores no domicílio } \\
\hline 1 & 5.777 & 0,031 & 0,0000 & 0,0027 & 0,1640 & 0,2329 \\
\hline 2 a 3 & 60.486 & 0,323 & 0,2225 & 0,4491 & 0,4342 & 0,3454 \\
\hline 4 ou mais & 121.001 & 0,646 & 0,7775 & 0,5482 & 0,4018 & 0,4217 \\
\hline \multicolumn{7}{|c|}{ Número de bens de consumo ${ }^{2}$} \\
\hline 0 & 6 & 0,000 & 0,0000 & 0,0000 & 0,0000 & 0,1023 \\
\hline 1 & 234 & 0,001 & 0,0000 & 0,0000 & 0,0000 & 0,0312 \\
\hline 2 & 1.343 & 0,007 & 0,0002 & 0,0000 & 0,0000 & 0,1167 \\
\hline 3 & 4.734 & 0,025 & 0,0446 & 0,0000 & 0,0285 & 0,0339 \\
\hline 4 & 16.104 & 0,086 & 0,1625 & 0,0000 & 0,0936 & 0,0596 \\
\hline 5 & 37.814 & 0,202 & 0,3528 & 0,0000 & 0,2999 & 0,1685 \\
\hline 6 & 46.852 & 0,250 & 0,4318 & 0,0495 & 0,3165 & 0,1218 \\
\hline 7 & 36.076 & 0,193 & 0,0081 & 0,3768 & 0,1980 & 0,1678 \\
\hline 8 & 27.583 & 0,147 & 0,0000 & 0,3436 & 0,0635 & 0,0813 \\
\hline 9 & 16.518 & 0,088 & 0,0000 & 0,2301 & 0,0000 & 0,1170 \\
\hline \multicolumn{7}{|c|}{$\begin{array}{l}\text { Rendimento mensal familiar } \\
\text { per capita (salário-mínimo) }\end{array}$} \\
\hline Menos de um 1/4 & 9.670 & 0,052 & 0,0972 & 0,0000 & 0,0533 & 0,1326 \\
\hline De $1 / 4$ a $1 / 2$ & 19.001 & 0,101 & 0,1779 & 0,0000 & 0,1630 & 0,1083 \\
\hline De $1 / 2$ a 1 & 42.886 & 0,229 & 0,3834 & 0,0000 & 0,3249 & 0,1171 \\
\hline De 1 a 2 & 48.705 & 0,260 & 0,3414 & 0,1489 & 0,2810 & 0,1366 \\
\hline De 2 a 3 & 21.577 & 0,115 & 0,0000 & 0,2901 & 0,0970 & 0,1425 \\
\hline De 3 a 5 & 18.849 & 0,101 & 0,0000 & 0,2256 & 0,0307 & 0,1195 \\
\hline De 5 a 10 & 13.970 & 0,075 & 0,0000 & 0,1712 & 0,0501 & 0,1429 \\
\hline Mais de 10 & 12.606 & 0,067 & 0,0000 & 0,1642 & 0,0000 & 0,1004 \\
\hline
\end{tabular}

(Continua) 
Anexo 1

Continuação

\begin{tabular}{|c|c|c|c|c|c|c|}
\hline \multirow[t]{2}{*}{ Fatores e variáveis } & \multicolumn{2}{|c|}{ Freqüência marginal } & \multicolumn{3}{|c|}{ Perfis extremos } & \multirow[b]{2}{*}{4} \\
\hline & Absoluta & Relativa & 1 & 2 & 3 & \\
\hline \multicolumn{7}{|c|}{$\begin{array}{l}\text { Tem algum direito a algum plano } \\
\text { de saúde (médico ou odontológico) }\end{array}$} \\
\hline Sim & 58.107 & 0,310 & 0,0348 & 0,6262 & 0,2066 & 0,6353 \\
\hline Não & 129.157 & 0,690 & 0,9652 & 0,3738 & 0,7934 & 0,3647 \\
\hline \multicolumn{7}{|c|}{$\begin{array}{l}\text { De necessidade } \\
\text { De um modo geral, considera } \\
\text { seu próprio estado de saúde } 3\end{array}$} \\
\hline Bom & 140.247 & 0,749 & 0,8926 & 0,9238 & 0,1423 & 0,3252 \\
\hline Regular & 38.884 & 0,208 & 0,1074 & 0,0000 & 0,6609 & 0,3324 \\
\hline Ruim & 8.133 & 0,043 & 0,0000 & 0,0762 & 0,1969 & 0,3425 \\
\hline \multicolumn{7}{|c|}{$\begin{array}{l}\text { Nas duas últimas semanas, } \\
\text { quantos dias esteve acamado? }\end{array}$} \\
\hline 0 & 179.746 & 0,960 & 1,0000 & 0,9998 & 0,8055 & 0,5466 \\
\hline 1 & 1.223 & 0,007 & 0,0000 & 0,0002 & 0,0000 & 0,0931 \\
\hline 2 & 1.619 & 0,009 & 0,0000 & 0,0000 & 0,0857 & 0,1682 \\
\hline 3 ou mais & 4.676 & 0,025 & 0,0000 & 0,0000 & 0,1088 & 0,1921 \\
\hline \multicolumn{7}{|c|}{$\begin{array}{l}\text { Qual o principal motivo que } \\
\text { o impediu de realizar suas } \\
\text { atividades habituais? }\end{array}$} \\
\hline Doença & 9.845 & 0,053 & 0,0000 & 0,0000 & 0,2323 & 0,3758 \\
\hline Causas externas & 812 & 0,004 & 0,0000 & 0,0000 & 0,1445 & 0,2218 \\
\hline Outras & 1.511 & 0,008 & 0,0000 & 0,0000 & 0,0666 & 0,1195 \\
\hline Não se aplica & 175.096 & 0,935 & 1,0000 & 1,0000 & 0,5567 & 0,2829 \\
\hline \multicolumn{7}{|l|}{$\begin{array}{l}\text { Número de doenças } \\
\text { crônicas citadas } 4\end{array}$} \\
\hline 0 & 118.961 & 0,635 & 0,8138 & 0,8128 & 0,0935 & 0,0415 \\
\hline 1 & 39.217 & 0,209 & 0,1862 & 0,1872 & 0,2612 & 0,1195 \\
\hline 2 & 17.380 & 0,093 & 0,0000 & 0,0000 & 0,3523 & 0,1730 \\
\hline 3 & 7.665 & 0,041 & 0,0000 & 0,0000 & 0,1985 & 0,0812 \\
\hline 4 & 3.105 & 0,017 & 0,0000 & 0,0000 & 0,0826 & 0,1532 \\
\hline 5 & 799 & 0,004 & 0,0000 & 0,0000 & 0,0118 & 0,2117 \\
\hline 6 & 131 & 0,001 & 0,0000 & 0,0000 & 0,0000 & 0,0672 \\
\hline 7 & 6 & 0,000 & 0,0000 & 0,0000 & 0,0000 & 0,1528 \\
\hline \multicolumn{7}{|c|}{ Número de outras doenças 5} \\
\hline 0 & 163.207 & 0,872 & 0,9755 & 0,9265 & 0,6527 & 0,3729 \\
\hline 1 & 21.332 & 0,114 & 0,0245 & 0,0735 & 0,3080 & 0,3121 \\
\hline 2 & 2.537 & 0,014 & 0,0000 & 0,0000 & 0,0393 & 0,1468 \\
\hline 3 & 188 & 0,001 & 0,0000 & 0,0000 & 0,0000 & 0,1682 \\
\hline
\end{tabular}

Normalmente, por problema de saúde, tem dificuldade para alimentar-se, tomar banho ou ir ao banheiro?

$\begin{array}{lrlllll}\text { Não consegue } & 770 & 0,004 & 0,0000 & 0,0000 & 0,0369 & 0,0774 \\ \text { Tem grande dificuldade } & 1.781 & 0,010 & 0,0000 & 0,0000 & 0,2339 & 0,1286 \\ \text { Tem pequena dificuldade } & 4.355 & 0,023 & 0,0000 & 0,0000 & 0,1674 & 0,0000 \\ \text { Não tem dificuldade } & 180.329 & 0,963 & 1,0000 & 1,0000 & 0,5618 & 0,3974 \\ \text { Não respondeu } & 29 & 0,000 & 0,0000 & 0,0000 & 0,0000 & 0,3965\end{array}$

(Continua) 
Anexo 1

Continuação

\begin{tabular}{|c|c|c|c|c|c|c|}
\hline \multirow[t]{2}{*}{ Fatores e variáveis } & \multicolumn{2}{|c|}{ Freqüência marginal } & \multicolumn{3}{|c|}{ Perfis extremos } & \multirow[b]{2}{*}{4} \\
\hline & Absoluta & Relativa & 1 & 2 & 3 & \\
\hline \multicolumn{7}{|c|}{$\begin{array}{l}\text { Normalmente, por problema de saúde, } \\
\text { tem dificuldade para correr, levantar } \\
\text { objetos pesados, praticar esportes } \\
\text { ou realizar trabalhos pesados? }\end{array}$} \\
\hline Não consegue & 6.634 & 0,035 & 0,0000 & 0,0000 & 0,1844 & 0,0734 \\
\hline Tem grande dificuldade & 13.861 & 0,074 & 0,0000 & 0,0000 & 0,2994 & 0,0259 \\
\hline Tem pequena dificuldade & 19.852 & 0,106 & 0,0000 & 0,0163 & 0,3275 & 0,3288 \\
\hline Não tem dificuldade & 144.337 & 0,771 & 1,0000 & 1,0000 & 0,1886 & 0,3900 \\
\hline Não respondeu & 2.580 & 0,014 & 0,0000 & 0,0000 & 0,0000 & 0,1818 \\
\hline
\end{tabular}

Normalmente, por problema de saúde, tem dificuldade para empurrar mesa ou realizar consertos domésticos?

Não consegue
Tem grande dificuldade
Tem pequena dificuldade
Não tem dificuldade
Não respondeu

4.872

0,009

\section{0,0000}

0,0000

0,0541

0,0330

11.928

0,026

0,0000

0,0000

0,2455

0,2222

66.110

0,064

0,0000

0,0000

0,3181

0,2550

0,887

1,0000

1,0000

0,3823

0,1850

Normalmente, por problema de saúde, tem dificuldade para subir

ladeira ou escada?

Não consegue
Tem grande dificuldade
Tem pequena dificuldade
Não tem dificuldade
Não respondeu

0,0000

0,0665

0,2398

Normalmente, por problema de saúde, tem dificuldade para abaixar-se,

ajoelhar-se ou curvar-se?

$\begin{array}{lrlllll}\text { Não consegue } & 1.836 & 0,010 & 0,0000 & 0,0000 & 0,0549 & 0,0602 \\ \text { Tem grande dificuldade } & 8.748 & 0,047 & 0,0000 & 0,0000 & 0,3423 & 0,1424 \\ \text { Tem pequena dificuldade } & 16.364 & 0,087 & 0,0000 & 0,0000 & 0,3659 & 0,1907 \\ \text { Não tem dificuldade } & 157.736 & 0,842 & 1,0000 & 1,0000 & 0,2023 & 0,4312 \\ \text { Não respondeu } & 2.580 & 0,014 & 0,0000 & 0,0000 & 0,0346 & 0,1754\end{array}$

Normalmente, por problema de saúde, tem dificuldade para andar mais

do que um quilômetro?

$\begin{array}{lrlllll}\text { Não consegue } & 2.304 & 0,012 & 0,0000 & 0,0000 & 0,0644 & 0,2175 \\ \text { Tem grande dificuldade } & 7.102 & 0,038 & 0,0000 & 0,0000 & 0,2213 & 0,3900 \\ \text { Tem pequena dificuldade } & 12.083 & 0,065 & 0,0000 & 0,0000 & 0,4330 & 0,1427 \\ \text { Não tem dificuldade } & 163.195 & 0,871 & 1,0000 & 1,0000 & 0,2642 & 0,0590 \\ \text { Não respondeu } & 2.580 & 0,014 & 0,0000 & 0,0000 & 0,0171 & 0,1908 \\ \text { Normalmente, por problema de saúde } & & & & & & \\ \text { em dificuldade para andar cerca } & & & & & & \\ \text { N } 100 \text { metros? } & 456 & 0,002 & 0,0000 & 0,0000 & 0,0294 & 0,1419 \\ \text { Não consegue } & 1.831 & 0,010 & 0,0000 & 0,0000 & 0,0843 & 0,1313 \\ \text { Tem grande dificuldade } & 5.248 & 0,028 & 0,0000 & 0,0000 & 0,3083 & 0,0000 \\ \text { Tem pequena dificuldade } & 177.149 & 0,946 & 1,0000 & 1,0000 & 0,5779 & 0,4740 \\ \text { Não tem dificuldade } & 2.580 & 0,014 & 0,0000 & 0,0000 & 0,0000 & 0,2529 \\ \text { Não respondeu } & & & & & & \end{array}$

(Continua) 
Anexo 1

Continuação

\begin{tabular}{|c|c|c|c|c|c|c|}
\hline \multirow[t]{2}{*}{ Fatores e variáveis } & \multicolumn{2}{|c|}{ Freqüência marginal } & \multicolumn{3}{|c|}{ Perfis extremos } & \multirow[b]{2}{*}{4} \\
\hline & Absoluta & Relativa & 1 & 2 & 3 & \\
\hline \multicolumn{7}{|l|}{ Predisponentes } \\
\hline \multicolumn{7}{|c|}{ Condição na unidade domiciliar } \\
\hline Pessoa de referência & 70.836 & 0,378 & 0,3728 & 0,3272 & 0,4251 & 0,4355 \\
\hline Cônjuge & 50.408 & 0,269 & 0,1934 & 0,3199 & 0,3476 & 0,1330 \\
\hline Filho & 50.805 & 0,271 & 0,3470 & 0,3163 & 0,0000 & 0,0078 \\
\hline Outro parente & 14.030 & 0,075 & 0,0868 & 0,0366 & 0,1244 & 0,2521 \\
\hline $\begin{array}{l}\text { Agregado ou empregado } \\
\text { doméstico }\end{array}$ & 1.185 & 0,006 & 0,0000 & 0,0000 & 0,1029 & 0,1715 \\
\hline \multicolumn{7}{|c|}{$\begin{array}{l}\text { Condição de ocupação na semana } \\
\text { de referência para pessoas }\end{array}$} \\
\hline Ocupadas & 110.921 & 0,592 & 0,7717 & 0,5780 & 0,3412 & 0,2314 \\
\hline Desocupadas & 12.544 & 0,067 & 0,1867 & 0,0000 & 0,0000 & 0,2538 \\
\hline Não respondeu & 63.799 & 0,341 & 0,0415 & 0,4220 & 0,6588 & 0,5147 \\
\hline \multicolumn{7}{|c|}{$\begin{array}{l}\text { Posição na ocupação no trabalho } \\
\text { principal da semana de referência }\end{array}$} \\
\hline Trabalhador sem carteira & 44.140 & 0,236 & 0,5483 & 0,0477 & 0,1096 & 0,0597 \\
\hline Trabalhador com carteira & 49.564 & 0,265 & 0,2261 & 0,4078 & 0,0064 & 0,1386 \\
\hline Conta própria & 24.221 & 0,129 & 0,1672 & 0,0842 & 0,2309 & 0,2735 \\
\hline Empregador & 5.540 & 0,030 & 0,0000 & 0,0756 & 0,0192 & 0,1751 \\
\hline Não se aplica & 63.799 & 0,341 & 0,0584 & 0,3848 & 0,6339 & 0,3530 \\
\hline \multicolumn{7}{|l|}{ Anos de Estudo } \\
\hline Sem instrução & 18.759 & 0,100 & 0,0630 & 0,0000 & 0,3484 & 0,3624 \\
\hline 1 a 4 (primário) & 24.229 & 0,129 & 0,1777 & 0,0000 & 0,3319 & 0,4376 \\
\hline 5 a 8 (ginásio) & 62.084 & 0,332 & 0,5662 & 0,1250 & 0,2987 & 0,0799 \\
\hline 9 a 11 (segundo-grau) & 34.606 & 0,185 & 0,1931 & 0,2900 & 0,0211 & 0,0862 \\
\hline 12 ou mais (superior) & 47.586 & 0,254 & 0,0000 & 0,5850 & 0,0000 & 0,0339 \\
\hline \multicolumn{7}{|l|}{ Faixa Etária } \\
\hline $15-49$ & 144.743 & 0,773 & 0,9973 & 0,8960 & 0,1917 & 0,2591 \\
\hline $50-59$ & 19.949 & 0,107 & 0,0027 & 0,1040 & 0,2739 & 0,1874 \\
\hline $60-69$ & 13.091 & 0,070 & 0,0000 & 0,0000 & 0,3171 & 0,2547 \\
\hline $70-79$ & 6.903 & 0,037 & 0,0000 & 0,0000 & 0,1621 & 0,1757 \\
\hline 80 ou mais & 2.578 & 0,014 & 0,0000 & 0,0000 & 0,0551 & 0,1231 \\
\hline \multicolumn{7}{|l|}{ Sexo } \\
\hline Masculino & 88.866 & 0,475 & 0,6787 & 0,3201 & 0,3490 & 0,4222 \\
\hline Feminino & 98.398 & 0,525 & 0,3213 & 0,6799 & 0,6510 & 0,5778 \\
\hline \multicolumn{7}{|l|}{ Cor ou raça } \\
\hline Amarela ou indígena & 1.389 & 0,007 & 0,0000 & 0,0774 & 0,0681 & 0,5745 \\
\hline Branca & 110.695 & 0,591 & 0,4164 & 0,7905 & 0,6064 & 0,1367 \\
\hline Parda ou preta & 75.180 & 0,401 & 0,5836 & 0,1321 & 0,3255 & 0,2888 \\
\hline \multirow{2}{*}{\multicolumn{7}{|c|}{$\begin{array}{l}\text { Variáveis externas: consumo } \\
\text { de serviços de saúde } \\
\text { Gastos com Saúde }\end{array}$}} \\
\hline & & & & & & \\
\hline Não gastou & 124.658 & 0,666 & 0,8547 & 0,5313 & 0,3466 & 0,2277 \\
\hline 1 a 19 & 10.835 & 0,058 & 0,0524 & 0,0350 & 0,0981 & 0,3011 \\
\hline 20 a 149 & 29.745 & 0,159 & 0,0848 & 0,2008 & 0,3190 & 0,3118 \\
\hline 150 ou mais & 22.026 & 0,118 & 0,0081 & 0,2329 & 0,2363 & 0,1594 \\
\hline \multicolumn{7}{|c|}{$\begin{array}{l}\text { Costuma procurar o mesmo lugar, } \\
\text { médico ou serviço de saúde quando } \\
\text { está doente ou precisando } \\
\text { de atendimento de saúde? }\end{array}$} \\
\hline Sim & 132.827 & 0,709 & 0,5798 & 0,6322 & 0,6037 & 0,3612 \\
\hline Não & 54.437 & 0,291 & 0,4202 & 0,3678 & 0,3963 & 0,6388 \\
\hline
\end{tabular}

(Continua) 
Anexo 1

Continuação

\begin{tabular}{|c|c|c|c|c|c|c|}
\hline \multirow[t]{2}{*}{ Fatores e variáveis } & \multicolumn{3}{|c|}{ reqüência marginal } & \multicolumn{3}{|c|}{ rfis extremos } \\
\hline & Absoluta & Relativa & 1 & 2 & 3 & 4 \\
\hline \multicolumn{7}{|l|}{$\begin{array}{l}\text { Quando está doente ou precisando } \\
\text { de atendimento e saúde } \\
\text { costuma procurar: }\end{array}$} \\
\hline Farmácia & 2.727 & 0,015 & 0,1502 & 0,0010 & 0,0102 & 0,0181 \\
\hline Posto ou centro de saúde & 49.028 & 0,262 & 0,3265 & 0,0706 & 0,2877 & 0,1769 \\
\hline Consultório particular & 31.569 & 0,169 & 0,0090 & 0,3347 & 0,1225 & 0,0633 \\
\hline $\begin{array}{l}\text { Ambulatório ou consultório } \\
\text { de empresa ou sindicato }\end{array}$ & 2.657 & 0,014 & 0,0230 & 0,0104 & 0,0877 & 0,0111 \\
\hline $\begin{array}{l}\text { Ambulatório ou consultório } \\
\text { de clínica }\end{array}$ & 13.232 & 0,071 & 0,0423 & 0,1100 & 0,0674 & 0,1178 \\
\hline Ambulatório de hospital & 27.087 & 0,145 & 0,1367 & 0,1350 & 0,1721 & 0,1612 \\
\hline Pronto-socorro ou Emergência & 6.247 & 0,033 & 0,0359 & 0,0284 & 0,0341 & 0,1236 \\
\hline Agente comunitário de saúde & 155 & 0,001 & 0,0000 & 0,0000 & 0,0000 & 0,1068 \\
\hline Outro tipo de serviço & 125 & 0,001 & 0,0000 & 0,0000 & 0,0000 & 0,1219 \\
\hline Não se aplica & 54.437 & 0,291 & 0,2765 & 0,3098 & 0,2183 & 0,0992 \\
\hline \multicolumn{7}{|l|}{$\begin{array}{l}\text { Nos últimos } 12 \text { meses } \\
\text { consultou médico? }\end{array}$} \\
\hline Sim & 110.057 & 0,588 & 0,5576 & 0,5425 & 0,5154 & 0,8688 \\
\hline Não & 77.207 & 0,412 & 0,4424 & 0,4575 & 0,4846 & 0,1312 \\
\hline \multicolumn{7}{|l|}{$\begin{array}{l}\text { Quantas vezes consultou médico } \\
\text { nos últimos } 12 \text { meses? }\end{array}$} \\
\hline 0 & 77.207 & 0,412 & 0,5919 & 0,2477 & 0,1848 & 0,2610 \\
\hline 1 & 29.748 & 0,159 & 0,1875 & 0,1527 & 0,1318 & 0,2379 \\
\hline 2 & 24.782 & 0,132 & 0,0761 & 0,3277 & 0,1426 & 0,2543 \\
\hline 3 & 16.082 & 0,086 & 0,0545 & 0,0877 & 0,1637 & 0,1087 \\
\hline 4 ou mais & 39.445 & 0,211 & 0,0900 & 0,1842 & 0,3771 & 0,1381 \\
\hline \multicolumn{7}{|l|}{$\begin{array}{l}\text { Quando foi ao dentista } \\
\text { pela última vez? }\end{array}$} \\
\hline Menos de 1 ano & 70.021 & 0,374 & 0,2933 & 0,5310 & 0,2956 & 0,1186 \\
\hline De 1 a 2 anos & 42.543 & 0,227 & 0,2430 & 0,2911 & 0,0755 & 0,3057 \\
\hline 3 anos ou mais & 68.247 & 0,364 & 0,4202 & 0,1697 & 0,4112 & 0,2503 \\
\hline Nunca foi ao dentista & 6.453 & 0,034 & 0,0435 & 0,0083 & 0,2177 & 0,3254 \\
\hline \multicolumn{7}{|l|}{$\begin{array}{l}\text { Nas duas últimas semanas, procurou } \\
\text { algum lugar, serviço ou profissional } \\
\text { de saúde para atendimento } \\
\text { relacionado à própria saúde? }\end{array}$} \\
\hline Sim & 27.418 & 0,146 & 0,1512 & 0,2728 & 0,4092 & 0,5718 \\
\hline Não & 159.846 & 0,854 & 0,8488 & 0,7272 & 0,5908 & 0,4282 \\
\hline \multicolumn{7}{|l|}{$\begin{array}{l}\text { Qual foi o motivo principal pelo qual } \\
\text { procurou atendimento relacionado à } \\
\text { saúde nas duas últimas semanas? }\end{array}$} \\
\hline Exames de rotina ou de prevençã & ăo 10.677 & 0,057 & 0,0131 & 0,0575 & 0,1823 & 0,1693 \\
\hline Acidente ou lesão & 1.227 & 0,007 & 0,0000 & 0,0000 & 0,0000 & 0,2171 \\
\hline Problema odontológico & 3.184 & 0,017 & 0,0153 & 0,0275 & 0,0166 & 0,0482 \\
\hline Tratamento ou reabilitação & 3.351 & 0,018 & 0,3315 & 0,0000 & 0,0522 & 0,0643 \\
\hline Outros & 1.351 & 0,007 & 0,0000 & 0,0166 & 0,0001 & 0,0450 \\
\hline Doença & 7.628 & 0,041 & 0,0082 & 0,0147 & 0,1824 & 0,2696 \\
\hline Não se aplica & 159.846 & 0,854 & 0,6320 & 0,8837 & 0,5664 & 0,1865 \\
\hline
\end{tabular}

(Continua) 
Anexo 1

Continuação

\begin{tabular}{|c|c|c|c|c|c|c|}
\hline \multirow[t]{2}{*}{ Fatores e variáveis } & \multicolumn{2}{|c|}{ qüência marginal } & \multicolumn{3}{|c|}{ Perfis extremos } & \multirow[b]{2}{*}{4} \\
\hline & Absoluta & Relativa & 1 & 2 & 3 & \\
\hline \multicolumn{7}{|l|}{$\begin{array}{l}\text { Quantas vezes procurou atendimento } \\
\text { de saúde por este mesmo motivo } \\
\text { nas duas últimas semanas? }\end{array}$} \\
\hline 0 & 159.846 & 0,854 & 0,8937 & 0,7400 & 0,5397 & 0,3143 \\
\hline 1 & 18.310 & 0,098 & 0,0213 & 0,2363 & 0,2392 & 0,3115 \\
\hline 2 & 5.863 & 0,031 & 0,0132 & 0,0237 & 0,0789 & 0,3183 \\
\hline 3 ou mais & 3.245 & 0,017 & 0,0718 & 0,0000 & 0,1422 & 0,0559 \\
\hline \multicolumn{7}{|c|}{$\begin{array}{l}\text { Onde procurou o primeiro atendimento } \\
\text { de saúde por este mesmo motivo nas } \\
\text { duas últimas semanas? }\end{array}$} \\
\hline Farmácia & 379 & 0,002 & 0,0000 & 0,0000 & 0,0000 & 0,0593 \\
\hline Posto ou centro de saúde & 7.178 & 0,038 & 0,0218 & 0,0022 & 0,2731 & 0,1308 \\
\hline Consultório médico particular & 6.387 & 0,034 & 0,0000 & 0,0719 & 0,0443 & 0,0663 \\
\hline Consultório odontológico & 2.671 & 0,014 & 0,0249 & 0,0642 & 0,0000 & 0,0375 \\
\hline Consultório de outros & 179 & 0,001 & 0,0000 & 0,0000 & 0,0000 & 0,0277 \\
\hline Ambulatório ou consultório emp & pr. 558 & 0,003 & 0,0000 & 0,0000 & 0,0000 & 0,0362 \\
\hline Ambulatório ou consultório clín. & 3.117 & 0,017 & 0,0019 & 0,0175 & 0,0313 & 0,1518 \\
\hline Pronto-socorro & 1.246 & 0,007 & 0,1750 & 0,2300 & 0,2073 & 0,0791 \\
\hline Hospital & 5.353 & 0,029 & 0,0763 & 0,0005 & 0,0516 & 0,1195 \\
\hline Laboratório ou clínica & & & & & & \\
\hline para exames & 226 & 0,001 & 0,0000 & 0,0000 & 0,0591 & 0,0069 \\
\hline Atendimento domiciliar & 124 & 0,001 & 0,0000 & 0,0000 & 0,0000 & 0,1110 \\
\hline Não se aplica & 159.846 & 0,854 & 0,7000 & 0,6138 & 0,3332 & 0,1739 \\
\hline \multicolumn{7}{|l|}{$\begin{array}{l}\text { Nos últimos } 12 \text { meses, } \\
\text { esteve internado? }\end{array}$} \\
\hline Sim & 14.664 & 0,078 & 0,0931 & 0,0981 & 0,3510 & 0,4074 \\
\hline Não & 172.600 & 0,922 & 0,9069 & 0,9019 & 0,6490 & 0,5926 \\
\hline \multicolumn{7}{|l|}{$\begin{array}{l}\text { Qual foi o principal atendimento } \\
\text { de saúde que recebeu quando esteve } \\
\text { internado pela última vez nos } \\
\text { últimos } 12 \text { meses? }\end{array}$} \\
\hline Tratamento clínico & 6.461 & 0,035 & 0,0000 & 0,0000 & 0,1732 & 0,2513 \\
\hline Outros & 4.002 & 0,021 & 0,0203 & 0,0202 & 0,0314 & 0,1693 \\
\hline Cirurgia & 3.919 & 0,021 & 0,0000 & 0,0189 & 0,1105 & 0,2279 \\
\hline Tratamento psiquiátrico & 282 & 0,002 & 0,0000 & 0,0000 & 0,0283 & 0,0484 \\
\hline Não se aplica & 172.600 & 0,922 & 0,9797 & 0,9609 & 0,6566 & 0,3031 \\
\hline
\end{tabular}

Fonte: Pesquisa Nacional de Amostra por Domicílio, 1998.

Observações:

1 Não estão incluídas a região Norte e pessoas com menos de 15 anos.

2 A variável "bens de consumo" foi construída pela soma não ponderada dos seguintes itens: domicílio próprio, telefone, fogão, filtro de água, rádio, televisão a cores, geladeira, freezer, máquina de lavar roupa.

3 As categorias muito bom e bom da variável "auto-avaliação do estado de saúde" foram agrupadas na categoria de saúde boa e as categorias muito ruim e ruim foram agrupadas na categoria de saúde ruim.

4 Número de doenças crônicas construído pela soma de: doenças de coluna ou costas, artrite ou reumatismo, câncer,

diabetes, hipertensão, doenças do coração, doença renal crônica, cirrose.

5 Número de outras doenças construído pela soma de: depressão, tendinite ou tenossinovite, bronquite ou asma. 


\begin{tabular}{|c|c|c|c|c|c|c|c|c|c|c|c|}
\hline $\begin{array}{l}\text { Não } \\
\text { determinado }\end{array}$ & 25 & 39 & 24 & 12 & 91 & 12 & 55 & 6 & 33 & 10 & 28 \\
\hline P1.1 & 37 & 32 & 18 & 13 & 82 & 1 & 76 & 05 & 69 & 1 & 3 \\
\hline P2.1 & 32 & 35 & 19 & 14 & 85 & 5 & 68 & 05 & 59 & 4 & 9 \\
\hline MP12 & 23 & 44 & 21 & 12 & 91 & 1 & 71 & 06 & 34 & 7 & 23 \\
\hline MP13 & 40 & 31 & 18 & 12 & 81 & 1 & 67 & 05 & 73 & 0 & 1 \\
\hline MP14 & 44 & 19 & 11 & 25 & 88 & 15 & 69 & 05 & 78 & 0 & 3 \\
\hline P1.2 & 13 & 51 & 25 & 11 & 99 & 2 & 61 & 08 & 2 & 41 & 76 \\
\hline P2.2 & 21 & 44 & 23 & 12 & 95 & 8 & 54 & 07 & 10 & 24 & 57 \\
\hline MP21 & 22 & 46 & 21 & 12 & 95 & 1 & 68 & 07 & 17 & 14 & 41 \\
\hline MP23 & 17 & 50 & 23 & 10 & 98 & 3 & 46 & 08 & 5 & 35 & 68 \\
\hline MP24 & 4 & 54 & 35 & 8 & 100 & 4 & 65 & 08 & 8 & 38 & 65 \\
\hline P1.3 & 29 & 42 & 19 & 10 & 90 & 7 & 44 & 06 & 49 & 5 & 19 \\
\hline P2.3 & 26 & 40 & 21 & 13 & 88 & 13 & 52 & 06 & 40 & 10 & 28 \\
\hline MP31 & 36 & 34 & 20 & 11 & 81 & 2 & 60 & 05 & 68 & 0 & 2 \\
\hline MP32 & 17 & 52 & 21 & 10 & 98 & 4 & 44 & 07 & 8 & 27 & 61 \\
\hline MP34 & 26 & 26 & 28 & 20 & 84 & 43 & 26 & 05 & 52 & 9 & 25 \\
\hline P1.4 & 31 & 38 & 20 & 11 & 90 & 8 & 51 & 06 & 53 & 9 & 21 \\
\hline P2.4 & 20 & 51 & 17 & 12 & 90 & 0 & 60 & 06 & 42 & 9 & 17 \\
\hline MP41 & 39 & 26 & 17 & 19 & 85 & 1 & 79 & 05 & 77 & 1 & 2 \\
\hline MP42 & 18 & 49 & 21 & 12 & 99 & 4 & 59 & 08 & 7 & 34 & 66 \\
\hline MP43 & 29 & 46 & 12 & 13 & 91 & 1 & 39 & 06 & 56 & 1 & 4 \\
\hline MSP12 & 23 & 43 & 20 & 13 & 92 & 4 & 61 & 06 & 34 & 9 & 27 \\
\hline MSP13 & 28 & 36 & 22 & 13 & 87 & 6 & 59 & 06 & 49 & 4 & 12 \\
\hline MSP14 & 24 & 40 & 24 & 12 & 80 & 32 & 40 & 05 & 48 & 8 & 20 \\
\hline MSP23 & 19 & 46 & 22 & 13 & 95 & 8 & 52 & 07 & 18 & 16 & 45 \\
\hline MSP24 & 19 & 31 & 19 & 31 & 88 & 44 & 31 & 06 & 13 & 19 & 44 \\
\hline MSP34 & 20 & 27 & 27 & 27 & 80 & 57 & 27 & 05 & 53 & 17 & 43 \\
\hline
\end{tabular}

Fonte: Pesquisa Nacional de Amostra por Domicílio, 1998. 
Anexo 2.2

Proporção de pessoas segundo as categorias das variáveis do fator necessidade e perfis de consumo.

\begin{tabular}{|c|c|c|c|c|c|c|c|c|c|c|c|}
\hline \multirow[t]{2}{*}{ Perfis } & \multicolumn{3}{|c|}{ Auto-avalia saúde como } & \multicolumn{2}{|c|}{ Média de Doen. } & \multicolumn{5}{|c|}{ Não consegue ou tem grande dificuldade para } & \multirow[b]{2}{*}{$\begin{array}{l}\text { Andar } \\
100 \mathrm{~m}\end{array}$} \\
\hline & Boa & Ruim & $\begin{array}{c}\text { Esteve } \\
\text { acamado }\end{array}$ & Crônicas & Alimentar & Correr & $\begin{array}{l}\text { Emp. } \\
\text { mesa, }\end{array}$ & $\begin{array}{l}\text { Subir } \\
\text { lad. }\end{array}$ & Abaixar & $\begin{array}{l}\text { Andar } \\
1 \mathrm{~km}\end{array}$ & \\
\hline $\begin{array}{l}\text { Não } \\
\text { determinado }\end{array}$ & 43 & 11 & 25 & 1,1 & 0 & 18 & 3 & 7 & 5 & 4 & 1 \\
\hline P1.1 & 87 & 1 & 1 & 0,3 & 0 & 1 & 0 & 0 & 0 & 0 & 0 \\
\hline P2.1 & 67 & 3 & 9 & 0,6 & 0 & 5 & 0 & 1 & 1 & 1 & 0 \\
\hline MP12 & 95 & 0 & 0 & 0,2 & 0 & 0 & 0 & 0 & 0 & 0 & 0 \\
\hline MP13 & 44 & 5 & 1 & 1,1 & 0 & 19 & 2 & 6 & 6 & 4 & 0 \\
\hline MP14 & 36 & 42 & 63 & 1,2 & 28 & 0 & 0 & 0 & 0 & 0 & 0 \\
\hline P1.2 & 95 & 0 & 1 & 0,3 & 0 & 1 & 0 & 0 & 0 & 0 & 0 \\
\hline P2.2 & 69 & 2 & 9 & 0,7 & 0 & 7 & 1 & 1 & 1 & 1 & 0 \\
\hline MP21 & 97 & 0 & 0 & 0,2 & 0 & 0 & 0 & 0 & 0 & 0 & 0 \\
\hline MP23 & 56 & 2 & 1 & 1,3 & 0 & 25 & 5 & 8 & 8 & 5 & 1 \\
\hline MP24 & 73 & 23 & 19 & 1,2 & 58 & 0 & 0 & 0 & 0 & 0 & 0 \\
\hline P1.3 & 14 & 23 & 9 & 2,2 & 0 & 69 & 31 & 55 & 47 & 45 & 12 \\
\hline P2.3 & 21 & 22 & 29 & 1,9 & 0 & 56 & 20 & 38 & 31 & 28 & 6 \\
\hline MP31 & 29 & 10 & 2 & 1,5 & 0 & 42 & 8 & 22 & 16 & 13 & 2 \\
\hline MP32 & 39 & 6 & 2 & 1,6 & 0 & 43 & 15 & 24 & 22 & 18 & 4 \\
\hline MP34 & 1 & 86 & 95 & 3,7 & 0 & 91 & 65 & 84 & 74 & 77 & 32 \\
\hline P1.4 & 4 & 68 & 50 & 2,3 & 100 & 0 & 0 & 0 & 0 & 0 & 0 \\
\hline P2.4 & 27 & 12 & 1 & 1,0 & 98 & 0 & 0 & 0 & 0 & 0 & 0 \\
\hline MP41 & 53 & 16 & 3 & 0,5 & 94 & 0 & 0 & 0 & 0 & 0 & 0 \\
\hline MP42 & 53 & 14 & 10 & 0,8 & 98 & 0 & 0 & 0 & 0 & 0 & 0 \\
\hline MP43 & 0 & 25 & 1 & 2,2 & 100 & 0 & 0 & 0 & 0 & 0 & 0 \\
\hline MSP12 & 70 & 2 & 5 & 0,6 & 0 & 4 & 0 & 1 & 1 & 1 & 0 \\
\hline MSP13 & 39 & 9 & 14 & 1,3 & 0 & 25 & 4 & 9 & 8 & 6 & 1 \\
\hline MSP14 & 20 & 52 & 88 & 1,7 & 8 & 12 & 0 & 20 & 4 & 4 & 0 \\
\hline MSP23 & 45 & 7 & 11 & 1,3 & 0 & 27 & 5 & 9 & 9 & 7 & 1 \\
\hline MSP24 & 31 & 50 & 69 & 0,9 & 25 & 0 & 0 & 6 & 0 & 0 & 0 \\
\hline MSP34 & 3 & 80 & 93 & 3,1 & 0 & 67 & 40 & 63 & 50 & 47 & 23 \\
\hline
\end{tabular}

Fonte: Pesquisa Nacional de Amostra por Domicílio, 1998. 
Anexo 2.3

Proporção de pessoas segundo as categorias das variáveis do fator de predisposição e perfis de consumo.

\begin{tabular}{|c|c|c|c|c|c|c|c|c|c|c|c|c|}
\hline \multirow{2}{*}{ Tipologia } & \multicolumn{4}{|c|}{ Anos de estudo } & \multicolumn{4}{|c|}{ Grupo de idade } & \multicolumn{4}{|c|}{ Cor da pele } \\
\hline & Nenhum & De 1 a 4 & De 5 a 8 & $9 \mathrm{ou}+$ & 15 a 49 & 50 a 59 & 60 a 79 & $80 \mathrm{ou}+$ & Homens & $\begin{array}{c}\text { Amarela } \\
\text { ou indígena }\end{array}$ & $\begin{array}{l}\text { Parda ou } \\
\text { preta }\end{array}$ & Branca \\
\hline $\begin{array}{l}\text { Não } \\
\text { determinado }\end{array}$ & 12 & 17 & 40 & 31 & 61 & 20 & 17 & 1 & 36 & 1 & 41 & 58 \\
\hline P1.1 & 9 & 18 & 52 & 21 & 94 & 4 & 2 & 0 & 63 & 0 & 63 & 37 \\
\hline P2.1 & 11 & 17 & 48 & 24 & 83 & 10 & 6 & 0 & 42 & 0 & 48 & 52 \\
\hline MP12 & 2 & 6 & 40 & 52 & 95 & 4 & 1 & 0 & 57 & 1 & 44 & 56 \\
\hline MP13 & 26 & 27 & 41 & 7 & 64 & 19 & 16 & 1 & 37 & 0 & 60 & 40 \\
\hline MP14 & 32 & 21 & 43 & 4 & 81 & 13 & 7 & 0 & 47 & 0 & 82 & 18 \\
\hline $\mathrm{P} 1.2$ & 1 & 1 & 7 & 91 & 85 & 10 & 4 & 0 & 43 & 2 & 11 & 87 \\
\hline P2.2 & 5 & 8 & 28 & 59 & 66 & 18 & 16 & 1 & 38 & 1 & 29 & 70 \\
\hline MP21 & 1 & 3 & 27 & 69 & 94 & 5 & 1 & 0 & 50 & 1 & 35 & 65 \\
\hline MP23 & 6 & 12 & 22 & 60 & 39 & 27 & 31 & 3 & 29 & 2 & 14 & 85 \\
\hline MP24 & 12 & 4 & 0 & 85 & 69 & 15 & 12 & 4 & 54 & 4 & 12 & 85 \\
\hline P1.3 & 39 & 28 & 27 & 6 & 14 & 24 & 53 & 9 & 25 & 0 & 40 & 59 \\
\hline P2.3 & 21 & 23 & 35 & 21 & 41 & 23 & 31 & 4 & 32 & 1 & 42 & 57 \\
\hline MP31 & 31 & 29 & 36 & 5 & 49 & 24 & 26 & 1 & 36 & 0 & 55 & 45 \\
\hline MP32 & 11 & 18 & 28 & 43 & 28 & 26 & 40 & 5 & 27 & 1 & 20 & 80 \\
\hline MP34 & 42 & 19 & 34 & 4 & 24 & 21 & 43 & 11 & 27 & 2 & 38 & 60 \\
\hline P1.4 & 49 & 18 & 23 & 11 & 21 & 13 & 42 & 24 & 40 & 1 & 40 & 59 \\
\hline P2.4 & 31 & 20 & 29 & 20 & 44 & 22 & 30 & 4 & 48 & 0 & 36 & 64 \\
\hline MP41 & 36 & 23 & 35 & 7 & 86 & 4 & 7 & 3 & 57 & 0 & 63 & 37 \\
\hline MP42 & 30 & 7 & 14 & 49 & 61 & 10 & 14 & 14 & 42 & 2 & 19 & 79 \\
\hline MP43 & 49 & 34 & 17 & 1 & 2 & 22 & 69 & 7 & 20 & 1 & 39 & 61 \\
\hline MSP12 & 7 & 14 & 39 & 40 & 77 & 13 & 9 & 0 & 37 & 1 & 38 & 61 \\
\hline MSP13 & 20 & 22 & 40 & 18 & 60 & 21 & 18 & 1 & 35 & 1 & 49 & 50 \\
\hline MSP14 & 36 & 4 & 32 & 28 & 68 & 16 & 12 & 4 & 48 & 0 & 64 & 36 \\
\hline MSP23 & 11 & 16 & 36 & 38 & 48 & 24 & 26 & 2 & 32 & 1 & 31 & 68 \\
\hline MSP24 & 19 & 0 & 25 & 56 & 50 & 38 & 13 & 0 & 38 & 0 & 25 & 75 \\
\hline MSP34 & 30 & 27 & 17 & 27 & 47 & 13 & 27 & 13 & 30 & 0 & 57 & 43 \\
\hline
\end{tabular}

Fonte: Pesquisa Nacional de Amostra por Domicílio, 1998. 
Anexo 2.4

Proporção de pessoas segundo as categorias das variáveis de consumo de serviços de saúde e perfis de consumo.

\begin{tabular}{|c|c|c|c|c|c|c|c|c|c|}
\hline \multirow[t]{2}{*}{ Perfis } & \multicolumn{3}{|c|}{ Gastos com a saúde (Reais) } & \multirow{2}{*}{$\begin{array}{l}\text { Consultou } \\
\text { médico }\end{array}$} & \multirow{2}{*}{$\begin{array}{c}\text { Media } \\
\text { cons. médica }\end{array}$} & \multirow{2}{*}{$\begin{array}{l}\text { Dentista há } \\
\text { dois anos }\end{array}$} & \multirow{2}{*}{$\begin{array}{l}\text { Procurou } \\
\text { serv. saúde }\end{array}$} & \multirow{2}{*}{$\begin{array}{c}\text { Foi } \\
\text { internado }\end{array}$} & \multirow{2}{*}{$\begin{array}{l}\text { Número } \\
\text { de pessoas }\end{array}$} \\
\hline & 000-019 & 020-149 & $150 \mathrm{ou}+$ & & & & & & \\
\hline Não determinado & 66 & 22 & 12 & 74 & 2,2 & 53 & 29 & 13 & 1.996 \\
\hline P1.1 & 90 & 8 & 2 & 41 & 0,9 & 53 & 7 & 5 & 51.967 \\
\hline P2.1 & 84 & 12 & 4 & 59 & 1,5 & 54 & 16 & 10 & 7.559 \\
\hline MP12 & 81 & 13 & 6 & 45 & 1,0 & 68 & 7 & 4 & 16.682 \\
\hline MP13 & 85 & 13 & 2 & 66 & 1,7 & 38 & 14 & 10 & 5.837 \\
\hline MP14 & 79 & 17 & 4 & 71 & 2,3 & 51 & 46 & 22 & 72 \\
\hline P1.2 & 56 & 17 & 27 & 66 & 1,7 & 86 & 15 & 6 & 39.369 \\
\hline P2.2 & 56 & 20 & 24 & 73 & 2,0 & 69 & 23 & 10 & 4.895 \\
\hline MP21 & 74 & 15 & 11 & 52 & 1,2 & 76 & 9 & 5 & 17.071 \\
\hline MP23 & 47 & 23 & 30 & 81 & 2,4 & 64 & 24 & 10 & 3.687 \\
\hline MP24 & 58 & 12 & 31 & 65 & 1,7 & 65 & 19 & 8 & 26 \\
\hline P1.3 & 59 & 32 & 10 & 84 & 2,7 & 22 & 29 & 17 & 13.670 \\
\hline P2.3 & 55 & 29 & 16 & 85 & 2,7 & 40 & 38 & 20 & 3.313 \\
\hline MP31 & 78 & 19 & 3 & 74 & 2,1 & 33 & 20 & 12 & 4.422 \\
\hline MP32 & 45 & 27 & 28 & 84 & 2,7 & 52 & 29 & 12 & 3.355 \\
\hline MP34 & 41 & 40 & 19 & 95 & 3,4 & 27 & 65 & 42 & 184 \\
\hline P1.4 & 46 & 37 & 17 & 88 & 3,0 & 18 & 44 & 39 & 1.743 \\
\hline P2.4 & 67 & 25 & 8 & 79 & 2,5 & 34 & 23 & 20 & 236 \\
\hline MP41 & 86 & 11 & 3 & 59 & 1,5 & 37 & 14 & 10 & 191 \\
\hline MP42 & 49 & 23 & 28 & 77 & 2,4 & 54 & 28 & 22 & 181 \\
\hline MP43 & 59 & 36 & 5 & 84 & 2,6 & 12 & 23 & 23 & 179 \\
\hline MSP12 & 74 & 17 & 9 & 63 & 1,7 & 61 & 17 & 9 & 5.407 \\
\hline MSP13 & 75 & 20 & 5 & 73 & 2,1 & 42 & 23 & 12 & 2.782 \\
\hline MSP14 & 76 & 16 & 8 & 88 & 2,8 & 28 & 64 & 28 & 25 \\
\hline MSP23 & 53 & 25 & 22 & 77 & 2,3 & 54 & 28 & 13 & 2.369 \\
\hline MSP24 & 38 & 50 & 13 & 94 & 3,0 & 63 & 44 & 25 & 16 \\
\hline MSP34 & 50 & 20 & 30 & 100 & 3,5 & 43 & 67 & 33 & 30 \\
\hline
\end{tabular}

Fonte: Pesquisa Nacional de Amostra por Domicílio, 1998. 